\title{
Opening Editorial to the Special Issue on Transnational Risks and Multilevel Governance
}

This Special Issue of the European Journal of Risk Regulation is the offspring of a conference held at the European University Institute (EUI) in May 2012, where an interdisciplinary group of established scholars and practitioners in the field of risk regulation and governance debated for two days questions related to the governance of risks in a globalised society. The conference was organised within the framework of the HIIL project on transnational private regulation and tried to describe the changes of actors, instruments and effects of risk regulation at the transnational level. ${ }^{1}$

The expansion of global trade in services and commodities has increased the transnational dimension of risks; in turn, the hard and fast transmission of risks across boundaries creates the necessity for a coordinated response. Cooperation at the international level might not prevent risks from spreading, but it may minimise or reduce their negative effects. However, cooperation does not always suffice and centralised governance may be necessary instead. Yet, important tensions remain between having more centralised systems to assess and manage risks, which may enable the further integration of markets, and more decentralised regimes, which are more responsive to cultural differences and diverse local conditions (e.g. different exposures to risks).

To better understand the nature of those tensions, the EUI conference explored how different regulatory fora (including public and private regulators, public-private partnerships, international regulatory networks and international organisations) deal with the transboundary nature of risks in different sectors (ranging from environmental and food safety regulation to the regulation of air traffic and financial markets). The goal was to map how institutions operate by looking inter alia at the degree of fragmentation/cooperation and possible regulatory gaps and overlaps in the sectors and regulatory fora discussed and by identifying similarities and differences between regulatory philosophies (e.g. technocratic vs. participatory models) that guide the shaping of risk regulation across different institutions and jurisdictions.

This Special Issue zooms in on the cross-comparative perspective of the questions discussed during the conference. This means to compare and contrast not only different jurisdictions but also different sectors, which are shaped by the increasing emergence of transnational risks. In the field of risk regulation, cross-comparative questions are deeply intertwined with the transnational nature of risks. Thus, our questions always link the comparative perspective with the transnational dimension that characterises this field of study: How do different nation states regulate risks and in what ways do these regulatory approaches interact and co-exist in the transnational arena? Are there

1 'Mapping the Global Regulatory Space for Risk Governance', EUI, Florence, 28-29 May 2012; scientific organisers Alessandra Arcuri, Fabrizio Cafaggi and Marta Simoncini; the event was co-sponsored by the Robert Schuman Centre, the Hiil project, the Global Governance Programme and the Max Weber Programme for Postdoctoral Studies. The programme of the Conference is available at: $<$ http://www.eui.eu/SeminarsAndEvents/ Index.aspx? eventid=74454>. We would like to thank all the participants to the Conference for their insightful inputs into our research questions. Thanks also to Cliff Wirajendi for his excellent editorial support. 
dominant models of risk governance in the international arena? How are risks governed in different sectors? How do transnational private actors contribute to risk regulation? Are such new forms of regulation replacing or complementing public regulation? How accountable and effective are both public and private actors in assessing and managing transnational risks? And, how are risks and responsibilities distributed in transnational contexts? Given the deep integration of markets and the transboundary nature of risks, nation states cannot shape independently their own models of risk regulation and governance. The national and regional differences - well documented by recent rich and wide comparative analysis between Europe and US - show the persistent divergence of regulatory choices in many areas. This brings to the front the necessity of developing principles that can mediate between different approaches to risk regulation both among states and among regimes led by transnational actors.

The first article of this Special Issue starts by identifying some of these regulatory approaches. In her contribution, Elizabeth Fisher juxtaposes a linear process of risk regulation, where risk assessment is conceived as a purely scientific endeavour, strictly preceding risk management, with 'an iterative process that constantly involved many scientific, socio-political and other inputs'. Fisher shows that ' $[t]$ he linear model of risk regulation has come to dominate much of the policy and legal discourse' and she identifies several reasons why this linear model has become hegemonic. The article lucidly argues that this status of affairs is undesirable and it is claimed that the relationship between values and technical analysis needs to be reimagined, possibly by integrating different expertise in the debate.

Against this background, the concept of 'epistemic subsidiarity', developed by Sheila Jasanoff in the second contribution to this Issue, seems of fundamental importance for reimagining risk regulation. By epistemic subsidiarity, Jasanoff advocates for a type of subsidiarity "that respects the "how" (and not merely the "what") of risk governance'. Such a principle may be particularly apt to cope with a pluralist transnational arena where different models of risk governance co-exist.

Jasanoff further identifies three models of epistemic subsidiaries, which link science and policy making in different ways: coexistence, cosmopolitanism and constitutionalism. These models however have limits and yet, in the words of the Author, '[t] hey do ... offer starting points for reflection - for rethinking how to manage the hard task of living together in relative safety and harmony, in the face of incomplete knowledge and global risks, without stamping out diverse ways of knowing and reasoning that mature societies have come to accept as foundational'.

The issues raised by these first two articles (Fisher, Jasanoff), play a role in the specific case studies discussed in the remaining contributions of this Special Issue. The article by Sara Poli focuses on the regulation of genetically modified organisms (GMOs) and clearly links to the issue raised by Jasanoff about the need for a principle of epistemic subsidiarity. The current attempt to reform a European centralised system of GMOs regulation arguably evidences the inadequacy of a regulatory framework insensitive to different risk cultures on this divisive technology. In her article Poli offers an accurate description of the evolution of the European regulatory regime in this field and identifies the problems that the proposed regime, moving towards a re-nationalisation of GMOs 
politics, currently faces. Future work in this area may attempt at investigating whether/to what extent the models of epistemic subsidiarity developed by Jasanoff could possibly resolve the current impasse of the GMOs regulatory policy.

Another important facet of risk regulation and governance in transnational regulatory spaces is the question of how regulatory regimes allocate responsibility and liability on the different institutions and actors involved in the regulatory process. These issues are treated by the last two contributions through sector specific analysis. Both contributions show how responsibilities and the connected liabilities are not always clearly established in transnational regulatory regimes; their findings, arguably relevant for other sectors as well, converge on the fact that it is urgent to rethink these legal frameworks in order to achieve safer and more resilient systems.

Anne Van Aaken compares the regulatory regimes for air traffic management (ATM) and financial markets. In both cases multiple actors are entrusted with regulatory competences, leading to situations where it is not always clear who bears responsibility for what. Both the ATM and the financial markets regulatory regimes deal with transnational services involving high risks and both include private actors in the regulatory regime, features common to many contemporary regulatory regimes. Van Aaken draws attention to the fact that 'clear assignment of responsibilities is not only a prerequisite of the rule of law for those harmed by the activities, but also a prerequisite of trust'. Her analysis, partly based on game theory, leads to the conclusion that a higher degree of centralisation could contextually enhance trust and clarify responsibilities.

Finally, the article by Marta Simoncini and Giuseppe Contissa analyses the role of liability regimes in risk regulation, focusing on the fascinating case of socio-technical systems (STS), i.e. 'integrated systems constituted by technical artefacts, social artefacts, and humans'. The authors discuss ATM as a paradigmatic case study for understanding the main challenges in designing a liability regime that can mediate the trade off between risk and safety, as conveyed by the interaction of humans and technology. The article combines a comparative analysis of the American and European regimes for ATM with an analysis of the problems related to the distribution of responsibilities in highly automated systems.

When addressing each particular domain of analysis, all the articles compare and contrast either different regulatory systems or different sectors of regulation, with the aim of shedding light on the main regulatory gaps and the common problems that risk governance entails. In this frame, a number of intertwined issues and sub-topics connect all the articles: from the relationship between science and law, technology and regulation, to the institutional articulation of risk management. Yet, the central theme which bonds all the contributions together is the transnational dimension of risks and the necessity to develop a better balance between competing values and goals in the existing multilevel regulatory regime. All the contributions point to some deficiencies of the existing regimes and show that new instruments and institutions are slowly emerging to provide alert when risks arise and spread. All articles, whilst from different perspectives, provide food for thoughts for regulatory reforms. Last, but not least, we would like to thank Alberto Alemanno for giving us the opportunity to share this body of research with the readers of the EJRR.

Alessandra Arcuri, Fabrizio Cafaggi and Marta Simoncini 